\title{
Thermal Conductivity of Lightweight Concrete Block with Various Cooling Agent
}

\author{
Masni A. Majid ${ }^{1 *}$, Aina Syafawati Roslan², Noor Azlina Abdul Hamid', \\ Norhafizah Salleh $^{1}$, Zalipah Jamellodin ${ }^{1}$
}

${ }^{1}$ Jamilus Research Center,

Universiti Tun Hussein Onn Malaysia, 86400 Parit Raja, Johor, MALAYSIA

${ }^{2}$ Faculty of Civil Engineering and Built Environment,

Universiti Tun Hussein Onn Malaysia, 86400 Parit Raja, Johor, MALAYSIA

*Corresponding Author

DOI: https://doi.org/10.30880/ijie.2020.12.09.016

Received 08 January 2020; Accepted 13 July 2020; Available online 26 December 2020

\begin{abstract}
Energy was the important sources to human life. Due to increases energy demand in daily life, the energy consumption was increase day by day because of the heat load from solar radiation and heat produced by people. Toward sustainable development, this research was carried out to develop a lightweight concrete (LWC) block with various cooling agent such as glycerine, propylene glycol, coconut shell and gypsum powder. Six lightweight concrete (LWC) block with the size $250 \mathrm{~mm}(\mathrm{~L}) \times 250 \mathrm{~mm}(\mathrm{~W}) \times 100 \mathrm{~mm}(\mathrm{~T})$ were tested for thermal conductivity value. From the experimental result, it shows that lightweight concrete (LCW) block with various cooling agent obtained thermal conductivity value of $0.17 \mathrm{~W} / \mathrm{mK}-0.36 \mathrm{~W} / \mathrm{mK}$ lower than thermal conductivity value for normal lightweight concrete $(0.8 \mathrm{~W} / \mathrm{mK})$ depending on concrete density. The lightweight concrete (LCW) block with cooling agent having low thermal conductivity value will reduce energy consumption in building.
\end{abstract}

Keywords: Thermal conductivity, lightweight concrete, cooling agent, low energy

\section{Introduction}

Energy conservation is essential on population growth and limited natural energy sources. One-third of the total energy consumption and 30\% of greenhouse gas (GHS) emissions are attributed to buildings in most countries [1], [2] where contribute to the global warming problem. Global warming was a serious threat to our earth that widely affects the environment especially in reaching a comfortable life. For living in a comfortable environment, the alternative way such as the uses of the air conditioner and fan is preferred. All of this needed to consume the electrical energy. The energy required for cooling and heating of the building which involving thermal comfort depend greatly on the thermos-physical properties of construction material [3]. Heat transfer is a vector quantity occurs through the mechanism of conduction, convection and radiation [4]. Thermal conductivity is a material's property that demonstrates its heat conduction capability [5]. Energy consumption in a building depends on the thermal conductivity values of the building materials [6]. Concrete is used in building materials twice as much as all other building materials such as plastic, wood and steel [7]. Concrete with low thermal conductivity reduces the heat transfer and energy consumptions in buildings [8]. 
The development in sustainable building is relatively slow despite these responses and demand. The way for the construction industry to reach the goals of sustainability is to introduce several welfares including better energy efficiency, improved quality of indoor environments, increased health and productivity and minimize resource usage into the construction development and through the period of the building [9]. A suggestion of an encouraging effort to make sure sustainable production and delivery of the construction industry products to fulfil these demands, the Green Building Mission endorsed lately by the Malaysian Government [10]. In finding the best way and solution to solve the thermal problem without the use of electrical energy and environmentally friendly, this study was conducted to investigate the thermal conductivity performance of a lightweight concrete block with the various application of cooling agent.

\section{Literature Review}

The addition of cooling agent in concrete significantly improved engineering thermal properties of the heat storage of concrete materials. The ability cooling agent in concrete to absorb heat was also enhanced. However, the cooling agent needs a longer time to get more effective in thermal conductivity process. The thermal conductivity of the cooling agent in concrete was determined by thermal conductivity test. According to EN-ISO 10456, thermal conductivity for normal concrete without any cooling agent is usually $0.80 \mathrm{~W} / \mathrm{mK}$ depending on concrete density [11].

Phase change material (PCM) could be defined as unique materials that store and release heat by means of latent heat by means of latent heat which is one of the greatest controlling approaches used to regulator building temperature within the everyday cycle. Proposed the first arrangement of materials used for thermal energy storing materials stating those used as PCM which was beneficial and generally used [12]. The basic appliance of PCM application in open cooling was for a decrease of high temperature inside buildings, as PCM consumed massive thermal capacity to absorb large amounts of heat and large ranges of melting temperatures [13].

Fig. 1(a) shows the $1 \%$ fiber content correlation among gypsum content and thermal conductivity. The figure demonstrations that increasing gypsum content caused the thermal conductivity slightly increased. The average thermal conductivity for the gypsum contents of $0 \%, 5 \%$ and $10 \%$ of unfired wheat straw reinforced earth bricks is $0.596,0.622$ and $0.638 \mathrm{~W} / \mathrm{mK}$ respectively. Fig. 1(b) displays the link $3 \%$ fiber content between gypsum content and thermal conductivity. The average thermal conductivities for gypsum substances of $0 \%, 5 \%$ and $10 \%$ of earth bricks reinforced with wheat straw are $0.310,0.415$ and $0.461 \mathrm{~W} / \mathrm{mK}$ respectively whereas the thermal conductivity for barley straw reinforced bricks are $0.314,0.424$ and $0.476 \mathrm{~W} / \mathrm{mK}$ respectively to gypsum fillings of $0 \%, 5 \%$ and $10 \%$ [14].

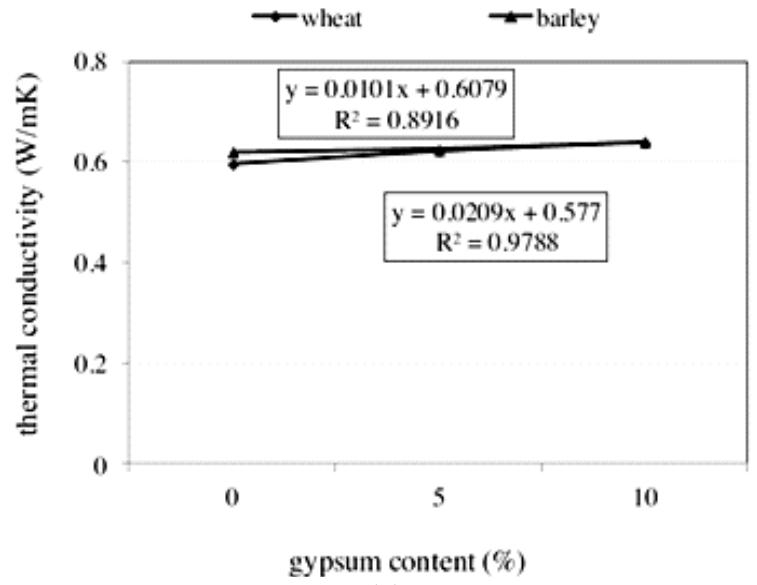

(a)

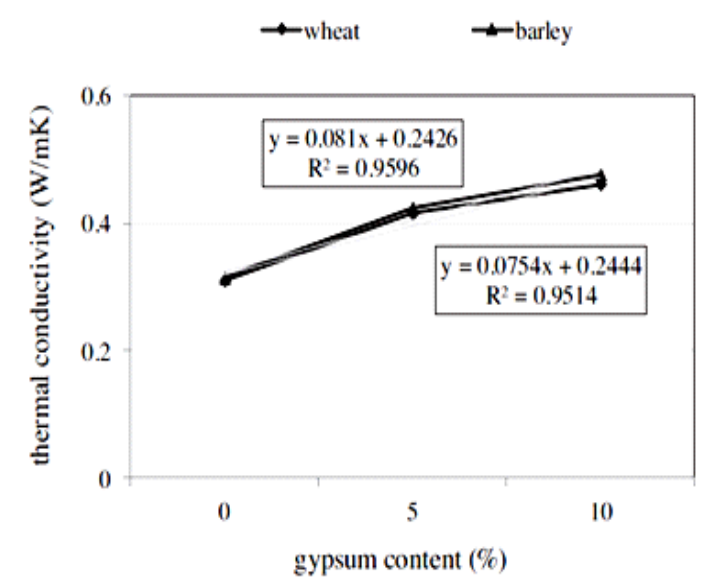

(b)

Fig.1 - (a) The consequence of gypsum and fibers at $1 \%$ on the thermal conductivity of bricks, (b) The influence of gypsum and $3 \%$ fibers content on the thermal conductivity of bricks

\subsection{Passive cooling system in building}

Cooling approaches might be categorized into three main sets which were active, passive and hybrid. Active strategies covered all conventional heating, ventilating and air-conditioning (HVACs) such as chillers. Moreover, passive cooling was recognized to the consumption of energy accessible from the normal environment relatively than the consumption of conventional energy capitals [15]. Passive cooling had been applied in building through means of heat deterrence saving (decreased heat absorption), thermal control (modifying heat gains) and heat intemperance (removal of internal heat). As shown in Fig. 2, thermal energy storage with PCMs was a heat modulation technique, one of the passive cooling methods [16]. 


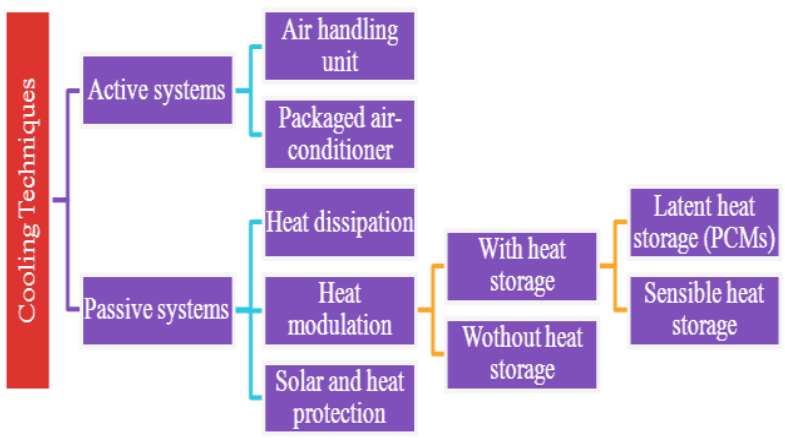

Fig. 2 - Different types of cooling techniques

\subsection{Thermal Conductivity}

In the chemical process, there is a transfer of energy in the form of heat. Heat transfer occurs in combination with other unit operations such as drying, distillation, combustion and evaporation. It occurs because temperature and heat differences flow from high temperature to low temperature [17]. Thermal conductivity can be defined as a flow rate rating process uniform heat as well as stable through a single unit surface due to the gradient of the temperature in the perpendicular direction of the unit wide surface. It also can be defined as the heat transfer rate for the thickness per unit temperature difference of a material. In general, the rate of calculating the heat flow velocity of the properties of a matter is also referred to as thermal conductivity. If the material has good conductor properties, then the material has high thermal conductivity value and vice versa. Thermal conductivity is determined as follows:

$$
k=\frac{Q \times L}{A \times \Delta T}
$$

where $k$ is the thermal conductivity of the specimen $(\mathrm{W} / \mathrm{mK}), Q$ is the amount of heat transfer through materials (W), $L$ is the thickness of the sample $(\mathrm{m}), A$ is the cross-sectional area of the specimen $\left(\mathrm{m}^{2}\right)$, and $\Delta T$ is the temperature difference between one side of the material to another $(\mathrm{K})$.

\section{Methodology}

\subsection{Materials Preparation}

The cooling block made up from lightweight concrete that mixed with admixture and various type of cooling agent was developed with the size of $250 \mathrm{~mm} \times 250 \mathrm{~mm} \times 100 \mathrm{~mm}$. In preparing the materials for the casting of cube and concrete blocks, the mix design of foamed concrete was intended to achieve targeted density less than $1600 \mathrm{~kg} / \mathrm{m}^{3}$. The materials including foam agent, Ordinary Portland Cement (OPC), aggregate, water, cooling agent (propylene glycol, glycerin, gypsum powder, coconut shell powder), tube and formwork as shown in Fig. 3. The type of tube used was reinforcement tube because of its high durability and could withstand the propylene glycol and glycerin. As for formwork, the size used same as the size of cooling blocks, $250 \mathrm{~mm} \times 250 \mathrm{~mm} \times 100 \mathrm{~mm}$ and the framework made from the waterproofing and high-quality plywood.

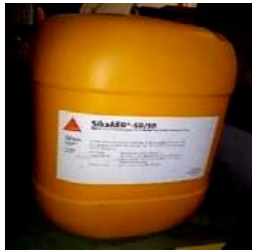

(a)

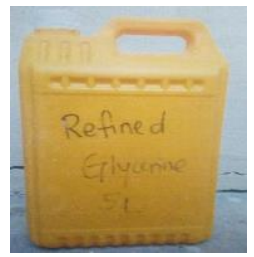

(e)

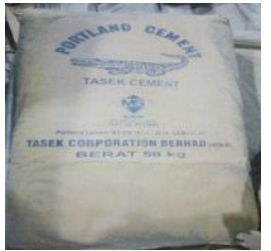

(b)

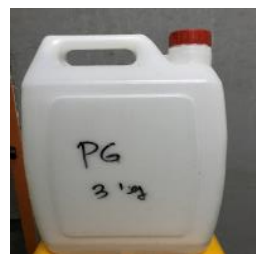

(e)

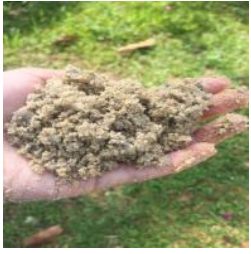

(c)

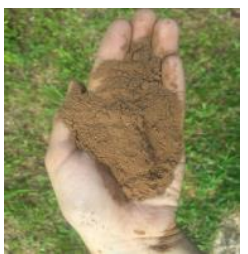

(g)

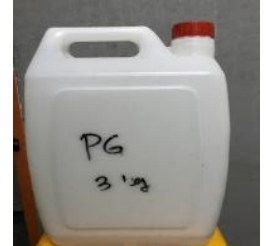

(d)

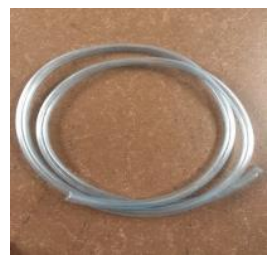

(h)

Fig. 3 - Materials in foamed concrete: (a) Foam agent, (b) Ordinary Portland Cement, (c) aggregate, (d) propylene glycol, (e) glycerin, (f) gypsum powder, (g) coconut shell powder, and (h) tube 
Lightweight concrete (LWC) is a conglomerate of lightweight cement and lightweight aggregates. It has a bulk density ranging between 300 and $2000 \mathrm{~kg} / \mathrm{m}^{3}$ compared to $2200-2600 \mathrm{~kg} / \mathrm{m}^{3}$ of normal weight concrete (NWC). Lightweight concrete (LWC) containing ordinary Portland cement (OPC) was used a binder. The OPC conforming to MS522, part-1-:2003 with a specific surface area and specific gravity. Foam agent was one of the materials used to cast the wall cooling panels. SikaAER - 50/50 foam agent was used for this research and it was synthetic foam agent. This foaming agent used for low strength of concrete. It chemical based was blend of synthetic surfactant send polymer.

Propylene Glycol, also called propane-1, 2-diol, is a synthetic organic compound with the chemical formula C3H802. It is a Phase Change Material (PCM) for cooling. It is a viscous colourless liquid which is nearly odourless but possesses a faintly sweet taste. The commercial product is a racemic mixture. Pure optical isomers can be obtained by hydration of optically pure propylene oxide. Glycerine is a water-soluble, colourless, odourless, viscosity with a boiling point. Glycerine was one of the phase change materials (PCM). Glycerine was the most important by-product during the production of biodiesel and its yield was considerably high. Glycerine played an accelerating role of reaction to the surrounding. Its melting point was $17.9^{\circ} \mathrm{C}$ and latent heat was $198.7 \mathrm{~kJ} / \mathrm{kg}$.

Park et al. [18] reported that the best final compressive strength was achieved with $10 \%$ of gypsum content. In this research, the cooling block was developing by using 5\% and $10 \%$ of gypsum content. The strength worsened beyond $10 \%$ gypsum content. Due to the pore-size refinement effect with a significant reduction in the large-sized pores around $100 \mu \mathrm{m}$ and a volume increase of significantly smaller pores in the nanometre sizes the $10 \%$ addition of gypsum improved the strength. Excessive addition of gypsum produced a more porous matrix with a lower strength due to coarser and wider crystals in the gypsum. Among the various agricultural straws due to its good thermal stability compared to other agricultural waste coconut shell could be very interesting material as a filler in biodegradable polymer composites.

\subsection{Casting of Cooling Blocks}

The cooling panel with dimension $250 \mathrm{~mm} \times 250 \mathrm{~mm} \times 100 \mathrm{~mm}$ had been cast. The casting of foamed concrete with a foaming agent and the installation of reinforcement tube and cooling agent (propylene glycol and glycerin) in the cooling block had been done before the thermal conductivity test. Table 1 shows the list of the sample, cooling block with a various mixture of the cooling agent.

Table 1 - Sample of the cooling block

\begin{tabular}{cc}
\hline Sample Code & List of Sample \\
\hline S1 & Lightweight Concrete $(\mathrm{LWC})+$ Propylene Glycol (PG) \\
\hline S2 & Lightweight Concrete $(\mathrm{LWC})+$ Glycerine $(\mathrm{GY})$ \\
\hline S3 & Lightweight Concrete $(\mathrm{LWC})+5 \%$ Gypsum Powder $(\mathrm{GP})+$ Glycerine $(\mathrm{GL})$ \\
\hline S4 & Lightweight Concrete $(\mathrm{LWC})+10 \%$ Gypsum Powder $(\mathrm{GP})+$ Glycerine $(\mathrm{GL})$ \\
\hline S5 & Lightweight Concrete $(\mathrm{LWC})+5 \%$ Gypsum Powder $(\mathrm{GP})+5 \%$ Coconut Shell Powder $(\mathrm{CSP})$ \\
\hline S6 & Lightweight Concrete $(\mathrm{LWC})+10 \%$ Gypsum Powder $(\mathrm{GP})+10 \%$ Coconut Shell Powder $(\mathrm{CSP})$ \\
\hline
\end{tabular}

The sixth cooling block was developed to further with the thermal conductivity test. The cooling block panel with the $250 \mathrm{~mm} \times 250 \mathrm{~mm} \times 100 \mathrm{~mm}$ was developed. The cooling blocks were different in term of the type of cooling agent used.

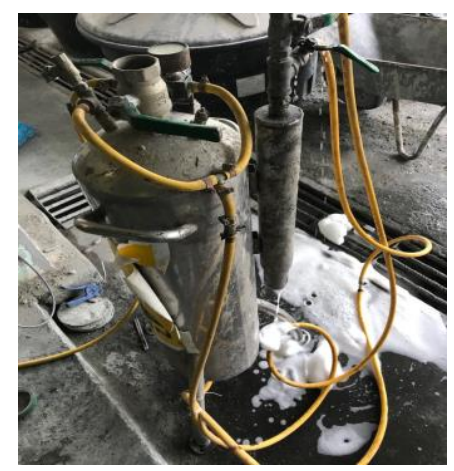

Fig. 4 - Foaming agent mix by using an air compressor 


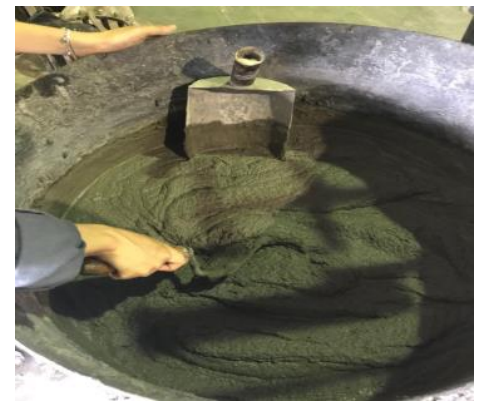

Fig. 5 - Mixture of lightweight concrete

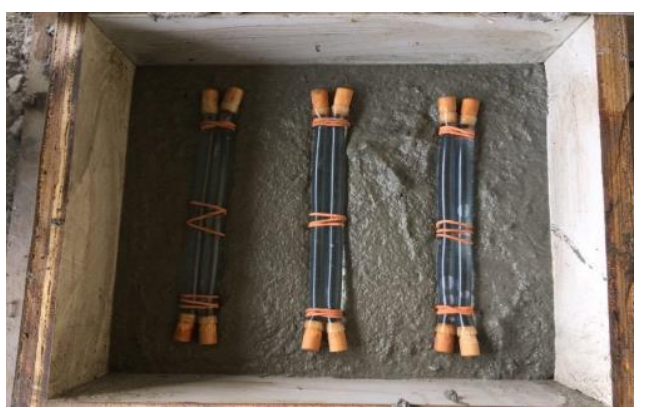

Fig. 7 - The arrangement of the tube containing propylene glycol and glycerine

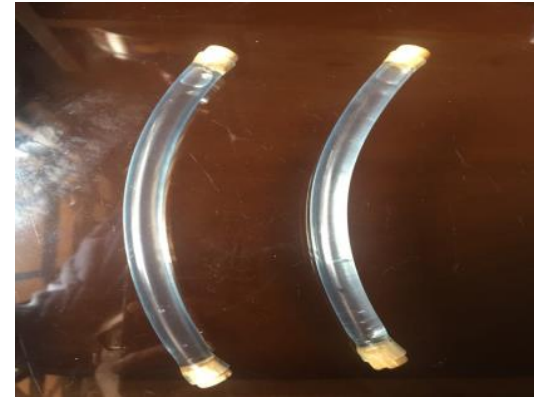

Fig.6 - Tube contains propylene glycol and glycerine

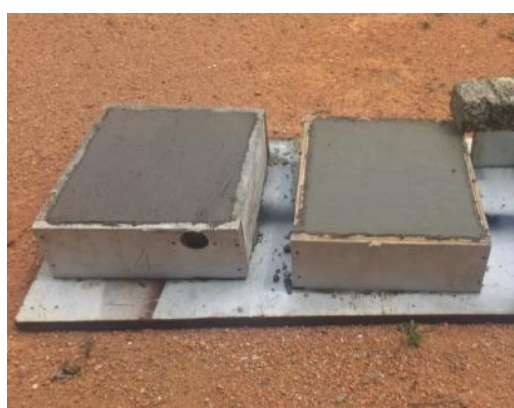

Fig. 8 - Casting of cooling blocks

\subsection{Testing on Foamed Concrete}

Slump flow test was one of requirement test to determine the consistency and rheology of concrete. According to the ASTM C1611/ C1611M, all of the results presented the pass result for slump flow test and it was acceptable Slump flow test is to determine the workability or consistency of concrete mix prepared at the laboratory or the construction site during the progress of the work. Concrete slump test is carried out from batch to batch to check the uniform quality of concrete during construction. Without any barrier, the flowability of self-compacting concrete was estimated by the slump flow test. The diameters require was shown in Fig. 9 below was the measurement required for all selfcompacting concrete. The self-compacting concrete should have the value for a slump between $500 \mathrm{~mm}$ to $850 \mathrm{~mm}$ whereas $T_{50}$ times is the time spend for the concrete to reach the $500 \mathrm{~mm}$ spread circle. Table This result was acceptable because the spreadability of fresh concrete mixes was in the limited range between $40 \%$ and $60 \%$ of 20 seconds for $500 \mathrm{~mm}$. Table 2 shows the summary result for slump flow test.

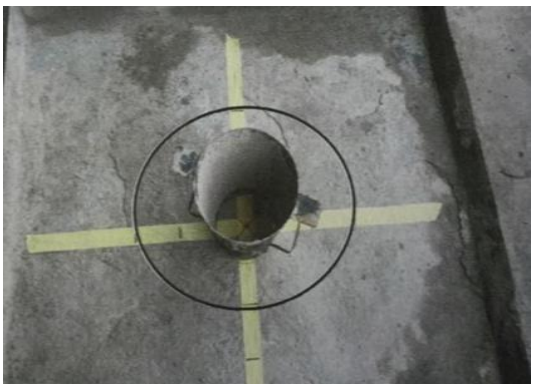

Fig. 9 - Slump flow test

Table 2 - Result of slump flow test

\begin{tabular}{cccc}
\hline Sample & Time (s) & Spread ability $(\mathbf{m m})$ & Result \\
\hline 1 & 10 & 465 & Pass \\
2 & 11 & 340 & Pass \\
3 & 10 & 405 & Pass \\
4 & 12 & 340 & Pass \\
\hline
\end{tabular}




\subsection{Thermal Conductivity Test}

The ability of the material to absorb heat is known as thermal conductivity. Thermal conductivity k-values can be determined from the maximum service limit of the refractory or room temperature to $1500 \circ \mathrm{C}$ or to the temperature at which the refractory is no longer dielectric. There are several factors that affected the thermal conductivity such as the density of the material, moisture of material and ambient temperature. Thermal conductivity value increases due to the increase of the density and moisture of material. As standard, the values stated in SI units are to be regarded.

The test sample should have a square plate with one side $250 \mathrm{~mm}$ as shown in Fig. 10. The upper and lower surface has to be smooth and flat. Place the test sample into the apparatus and put the copper plate before put on it insulating cover as shown in Fig.11. Tighten the insulation cover using a screw. Switch on the heating and connect USB port to the laptop then turn on the software. Thermal conductivity was conducted using the PicoLog software from the instrument and the data were taken from the data logger.

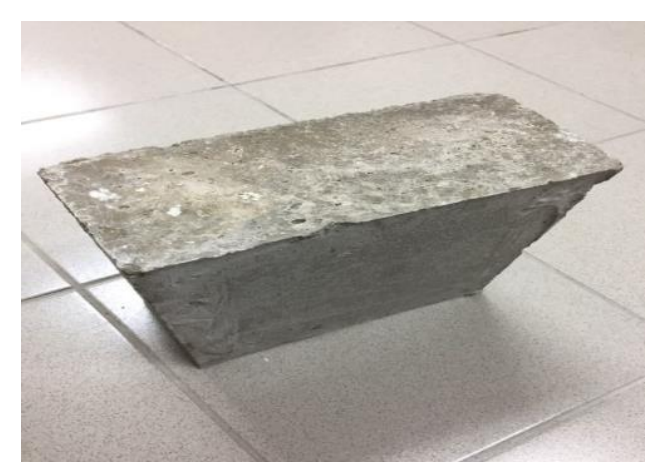

Fig. 10 - Sample of the cooling block
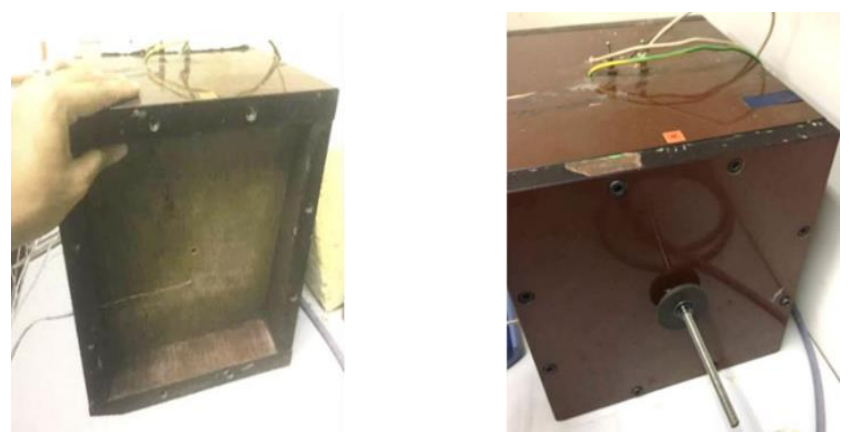

Fig. 11 - Thermal conductivity equipment

\section{Results and Analysis}

The thermal conductivity of the cooling agent in concrete was determined by thermal conductivity test. The size of the sample for thermal conductivity test is $250 \mathrm{~mm} \times 250 \mathrm{~mm} \times 100 \mathrm{~mm}$. The different temperature between each section is recorded for one and a half hours until the graph of temperature is maintained as shown in Fig. 12 to Fig. 17. The temperature difference between each section is calculated to determine the thermal conductivity value and summarized in as shown in Table 3.

Based on thermal conductivity test graph result for S1 shown in Fig. 12, the temperature of the heated channel and the cold channel are $38.43^{\circ} \mathrm{C}$ and $30.91^{\circ} \mathrm{C}$ respectively. The different of the temperature between hot and cold channel is $7.52^{\circ} \mathrm{C}$. While the thermal conductivity test results for $\mathrm{S} 2$ shown in Fig. 13. The temperature for the heated channel is $38.23^{\circ} \mathrm{C}$ and for the cold channel is $31.30^{\circ} \mathrm{C}$ while the temperature difference between hot and cold channel is $6.93{ }^{\circ} \mathrm{C}$. Fig. 14 shows thermal conductivity test graph result for $\mathrm{S} 3$, where the temperature of the heated channel is $38.36^{\circ} \mathrm{C}$ in the same time temperature of the cold channel is $28.53^{\circ} \mathrm{C}$ with the temperature difference of temperature is $15.69{ }^{\circ} \mathrm{C}$ of the hot and cold channel. As for S4, result for thermal conductivity test shown in Fig. 15 where the temperature for heat channel $42.00^{\circ} \mathrm{C}$ meanwhile temperature for the cold channel is $26.31^{\circ} \mathrm{C}$. Temperature different between hot and cold temperature is $15.69^{\circ} \mathrm{C}$.

Based on the S5, a thermal conductivity test graph result shown in Fig. 16 where the temperature of the heated channel is $33.10^{\circ} \mathrm{C}$ and the temperature cold channel is $25.51^{\circ} \mathrm{C}$. The different of the temperature is $7.59^{\circ} \mathrm{C}$ between hot and cold channel. Fig. 17 show the thermal conductivity test result for S6. The temperature of the heated channel is $40.99^{\circ} \mathrm{C}$ and cold temperature is $28.03^{\circ} \mathrm{C}$. The temperature difference is $12.96^{\circ} \mathrm{C}$ between hot and cold channel. Table 3 
shown the summary result for thermal conductivity test value for all sample; S1, S2, S3, S4, S5, S5. The example of calculation for thermal conductivity value is shown below:

$$
k=\frac{1.704 \mathrm{~W} \times 0.1 \mathrm{~m}}{0.0625 \mathrm{~m}^{2}[(38.43+273.13) K-(30.91+273.15)] K}=0.36 \mathrm{~W} / \mathrm{mK}
$$

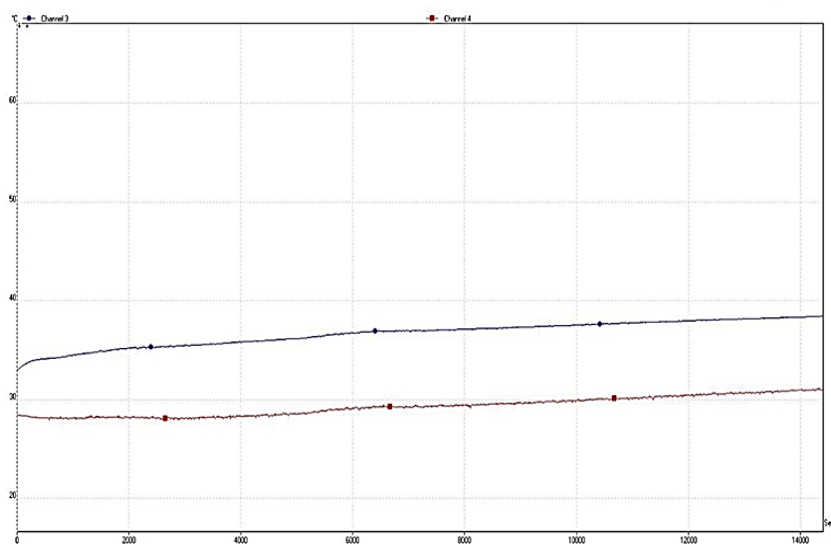

Fig. 12 - Temperature difference of S1

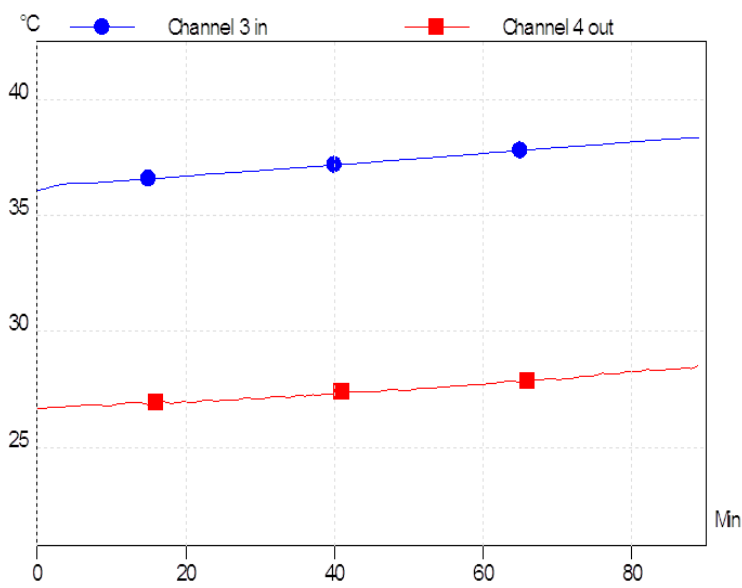

Fig. 14 - Temperature difference for S3

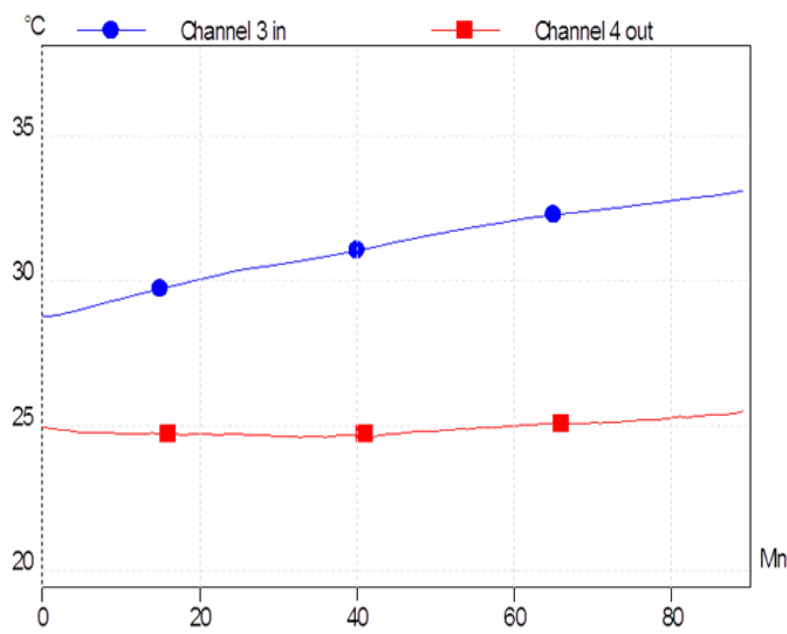

Fig. 16 - Temperature different for S5

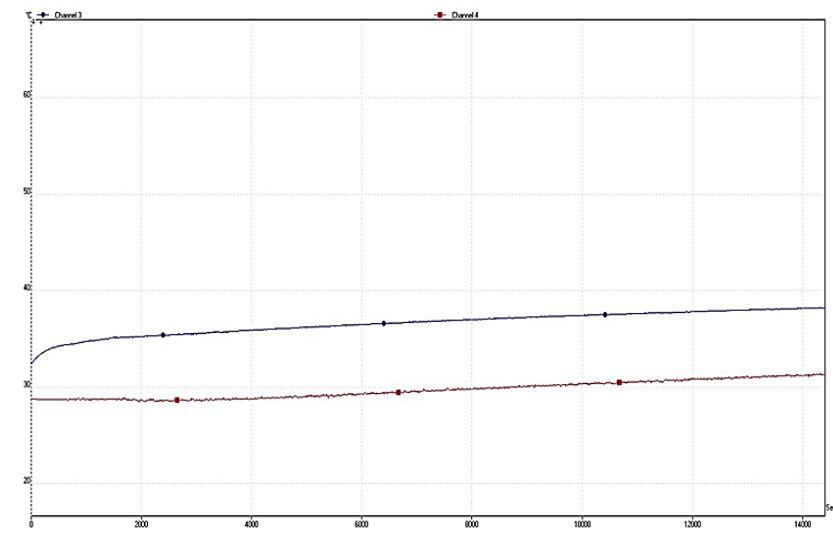

Fig. 13 - Temperature difference for $\mathrm{S} 2$

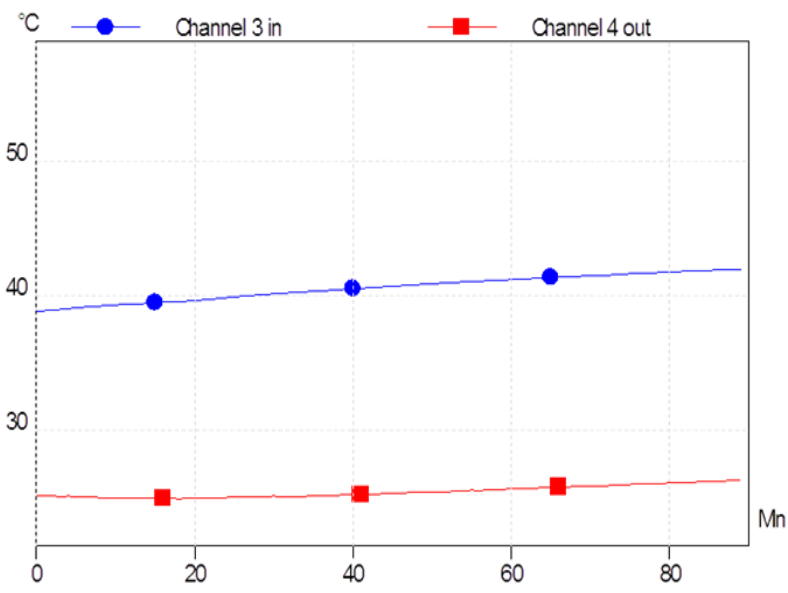

Fig. 15 - Temperature different of S4

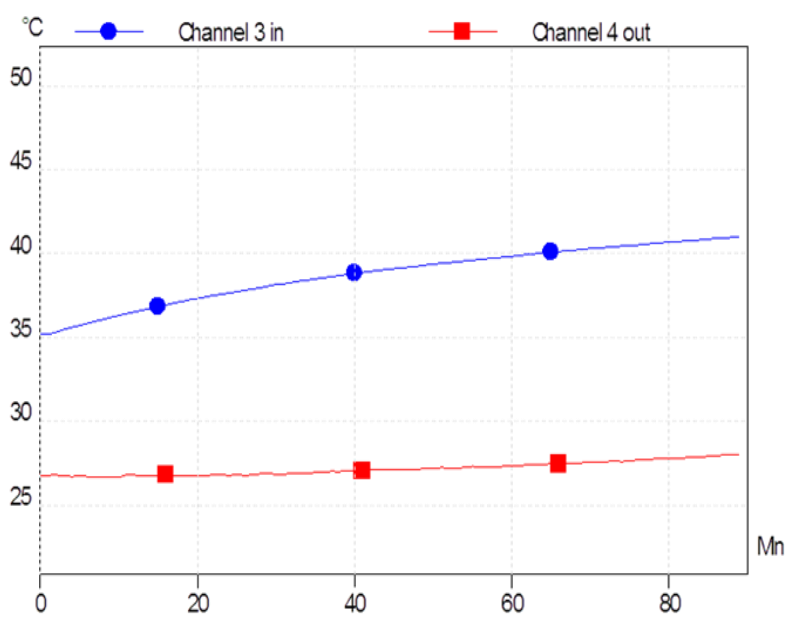

Fig. 17 - Temperature different for S6 
Table 3 - Summary result of thermal conductivity value

\begin{tabular}{ccccc}
\hline Sample & \multicolumn{2}{c}{$\begin{array}{c}\text { Temperature } \\
\left({ }^{\mathbf{o}} \mathbf{C}\right)\end{array}$} & $\begin{array}{c}\text { Temperature Difference, } \\
\Delta \boldsymbol{T}\left({ }^{\circ} \mathbf{C}\right)\end{array}$ & $\begin{array}{c}\text { Thermal Conductivity Value, } \\
\boldsymbol{k}(\mathbf{W} / \mathbf{m K})\end{array}$ \\
\cline { 2 - 3 } & Hot & $\mathbf{C o l d}$ & & 0.36 \\
S1 & 38.43 & 30.91 & 7.52 & 0.35 \\
S2 & 38.23 & 31.30 & 6.93 & 0.27 \\
S3 & 38.36 & 28.53 & 9.83 & 0.17 \\
S4 & 42.00 & 26.31 & 15.69 & 0.35 \\
S5 & 33.10 & 25.51 & 7.59 & 0.20 \\
S6 & 40.99 & 28.03 & 12.96 & \\
\hline
\end{tabular}

\section{Conclusion}

This experimental study was conducted to investigate the thermal conductivity of lightweight concrete block with various cooling agent. Based on the experimental work, the following conclusions are drawn:

- The best cooling agent in the lightweight concrete block is S4 which is a combination of $10 \%$ gypsum powder and glycerine.

- From thermal conductivity test, it is shown that S4 which contains $10 \%$ gypsum powder and glycerine give lowest thermal conductivity value which is $0.17 \mathrm{~W} / \mathrm{mK}$ and the highest is $\mathrm{S} 1$ which contains glycerine with the thermal conductivity value of $0.36 \mathrm{~W} / \mathrm{mK}$.

- The thermal conductivity value for lightweight concrete with the presence of the cooling agent in the liquid form (S3 and S4) show lower value compared to lightweight concrete with a cooling agent in the form of powder only (S5 and S6).

\section{Acknowledgement}

The authors have gratefully acknowledged the financial support provided by Universiti Tun Hussein Onn Malaysia through TIER 1 Vot. No. U839 research grant. Authors also want to thank the Faculty of Civil Engineering and Built Environment, Universiti Tun Hussein Onn Malaysia (UTHM) for continuous support to conduct this research.

\section{References}

[1] Ahn, Y. H., Jung, C. W., Suh, M., \& Jeon, M. H. (2016). Integrated construction process for green building. Procedia Engineering, 145(2016), 670-676.

[2] Ghoreishi, A. (2015). Assessment of thermal mass property for energy efficiency and thermal comfort in concrete office buildings. PhD Thesis, University of Illinois at Urbana-Champaign, pp 11-19.

[3] Latha, P. K., Darshana, Y., \& Venugopal, V. (2015). Role of building material in thermal comfort in tropical climates-A review. Journal of Building Engineering, 3, 104-113.

[4] Bergman, T. L., Incropera, F. P., Lavine, A. S., \& DeWitt, D. P. (2011). Introduction to heat transfer. John Wiley $\&$ Sons.

[5] Tong, X. C. (2011). Characterization methodologies of thermal management materials. In Advanced Materials for Thermal Management of Electronic Packaging. Springer, 59-129.

[6] Zhang, W., Min, H., Gu, X., Xi, Y., \& Xing, Y. (2015). Mesoscale model for thermal conductivity of concrete. Construction and Building Materials, 98, 8-16.

[7] Real, S., Gomes, M. G., Rodrigues, A. M., \& Bogas, J. A. (2016). Contribution of structural lightweight aggregate concrete to the reduction of thermal bridging effect in buildings. Construction and Building Materials, 121, 460470.

[8] Budaiwi, I., Abdou, A., \& Al-Homoud, M. (2002). Variations of thermal conductivity of insulation materials under different operating temperatures: Impact on envelope-induced cooling load. Journal of architectural engineering, 8(4), 125-132.

[9] Oktay, H., Yumrutaş, R., \& Akpolat, A. (2015). Mechanical and thermophysical properties of lightweight aggregate concretes. Construction and Building Materials, 96, 217-225.

[10] Shafii, F., \& Othman, M. Z. (2007). Sustainable building in the Malaysian context. In The International Conference on Sustainable Building Asia, Seoul, Korea.

[11] Young, H. D., Freedman, R. A., Sandin, T. R., \& Ford, A. L. (1996). University Physics. New York: AddisonWesley.

[12] Abhat, A. (1983). Low temperature latent heat thermal energy storage: heat storage materials. Solar energy, 30(4), 313-332. 
[13] Darkwa, J. (2009). Mathematical evaluation of a buried phase change concrete cooling system for buildings. Applied energy, 86(5), 706-711.

[14] Ashour, T., Korjenic, A., Korjenic, S., \& Wu, W. (2015). Thermal conductivity of unfired earth bricks reinforced by agricultural wastes with cement and gypsum. Energy and Buildings, 104, 139-146.

[15] Geetha, N. B., \& Velraj, R. (2012). Passive cooling methods for energy efficient buildings with and without thermal energy storage-A review. Energy Education Science and Technology Part A: Energy Science and Research, 29(2), 913-946.

[16] Akeiber, H., Nejat, P., Majid, M. Z. A., Wahid, M. A., Jomehzadeh, F., Famileh, I. Z., Calautit J. K., Hughrs B. R., \& Zaki, S. A. (2016). A review on phase change material (PCM) for sustainable passive cooling in building envelopes. Renewable and Sustainable Energy Reviews, 60, 1470-1497.

[17] Nag, P. K. (2013). Engineering thermodynamics. Tata McGraw-Hill Education.

[18] Park, H., Jeong, Y., Jun, Y., Jeong, J. H., \& Oh, J. E. (2016). Strength enhancement and pore-size refinement in clinker-free $\mathrm{CaO}$-activated GGBFS systems through substitution with gypsum. Cement and Concrete Composites, $68,57-65$.

[19] ISO 10456:2007 (2007). Building materials and products-Hygrothermal properties-Tabulated design values and procedures for determining declared and design thermal values. 